First Peoples Child \& Family Review

A Journal on Innovation and Best Practices in Aboriginal Child Welfare Administration,

Research, Policy \& Practice

\title{
A Review of the Literature on the Benefits and Drawbacks of Participatory Action Research
}

\section{Marlyn Bennett}

Volume 1, Number 1, 2004

URI: https://id.erudit.org/iderudit/1069582ar

DOI: https://doi.org/10.7202/1069582ar

See table of contents

Publisher(s)

First Nations Child and Family Caring Society of Canada

\section{ISSN}

1708-489X (print)

2293-6610 (digital)

Explore this journal

Cite this article

Bennett, M. (2004). A Review of the Literature on the Benefits and Drawbacks of Participatory Action Research. First Peoples Child \& Family Review, 1(1), 19-32. https://doi.org/10.7202/1069582ar
Article abstract

This paper reviews Participatory Action Research as a methodology. It maps the origins of Participatory Action Research (PAR) and discusses the benefits and challenges that have been identified by other researchers in utilizing PAR approaches in conducting research.
This document is protected by copyright law. Use of the services of Érudit (including reproduction) is subject to its terms and conditions, which can be viewed online.

https://apropos.erudit.org/en/users/policy-on-use/ 


\section{Abstract}

This paper reviews

Participatory Action

Research as a

methodology. It maps the

origins of Participatory

Action Research (PAR)

and discusses the benefits

and challenges that have

been identified by other

researchers in utilizing PAR

approaches in conducting

research.

\section{A Review of the Literature on the Benefits and Drawbacks of Participatory Action Research}

\section{Marlyn Bennett}

\section{Introduction}

Aboriginal people's view of researchers in general and anthropologists in particular, often extends beyond mere skepticism to contempt and distrust. In particular, the field of anthropology (and arguably others as well) is viewed by Aboriginal Peoples as being largely esoteric, irrelevant and incapable of contributing to solutions for the myriad of problems faced within Aboriginal communities (Warry 1990).

Research findings are often cloaked in academic jargon, are often unintelligible to communities and have largely been irrelevant to community needs. Academic reputations, so the argument goes, have been built on the backs of Aboriginal subjects and at the political and economic expense of Aboriginal communities. Aboriginal communities are now advocating research that is more collaborative and meaningful to their communities.

Awareness concerning the potential value of research varies enormously between Aboriginal communities (Warry 1990). Warry speculates that many communities have neither the inclination, nor the local expertise, to generate research agendas, or standards for local research (64). This is particularly true in the north, where, despite licensing by the Science Institute of the Northwest Territories, there still is, each summer, a massive influx of natural and social scientists. Inuit community inquiry groups often lack the time or the expertise to gauge the potential usefulness of the research or are unable to generate their own research agendas. Warry (1990) states that in contrasting the North with the South, a number of southern First Nations communities routinely enter into contractual relationships before allowing researchers to enter their communities. Aboriginal leaders clearly recognize that the information needs of their communities are obvious, but they denounce the monopolistic control of academia over the research process. Specifically, when the analysis and interpretation of research findings must take account of Indigenous science, which is based on experiential and humanistic interpretation, rather than academic needs (Colorado 1998, Warry 1990, and Stevenson, no date). In the quest to learn more about Indigenous Peoples and cultures, the resulting process and product of research has become a 


Participatory Action
Research is seen as
a flexible method that
complements the ideals
held by many academic
researchers in the various
fields of anthropology,
social sciences, history,
theology, economics,
philosophy, social work,
community and economic
development.

Participatory Action

Research is seen as a flexible method that complements the ideals held by many academic researchers in the various fields of anthropology, social sciences, history, theology, economics, philosophy, social work, community and economic development. commodity - it can be exchanged with universities, colleges, and publishers for a host of values, including advanced degrees, professional reputation, career mobility and book revenues (Richer 1988). Indigenous Peoples themselves have rarely capitalized on the commodification of their own cultural background and knowledge. When information appropriated by researchers from Indigenous sources becomes a commodity for private ends, it inherently becomes a process of alienation (Richer 1988) and ultimately, oppressive (Stevenson, no date).

Today, many Aboriginal communities will not indulge research that benefits only the researcher (Richer 1988). Indigenous Peoples believe they have been "researched to death" and will no longer tolerate colonial intrusion by researchers (Smith 1999; Royal Commission on Aboriginal Peoples, 1996; Richer 1988; and Flaherty, no date). Indigenous Peoples and communities are becoming more aggressive and in some areas, particularly now in the Northwest Territories and in Nunavut, researchers are required to apply for a license in order to conduct research in the North (Stevenson, no date; and Ward, 1996). These new research measures make it clear that Indigenous peoples now increasingly seek equal relationship in the research process and will no longer accept researchers who do not respect and honour that equality.

Research, whether it is formal or informal, should not perpetuate the status quo. Non-intrusive methods that are most conducive to the needs of the community should be advocated for which assists in the research process but at the same time is mindful not to continue to re-colonize participants in the process. Research methods chosen must include a process whereby members of the communities are given an opportunity to voice their opinions and be involved (but not superficially) in the research process throughout the life of any proposed project (St. Denis 1992). Participatory Action Research or PAR has been identified as one such method that is most conducive to doing research with Aboriginal peoples and communities. Participatory Action Research is seen as a flexible method that complements the ideals held by many academic researchers in the various fields of anthropology, social sciences, history, theology, economics, philosophy, social work, community and economic development (Fals-Borda 1992, Frideres 1992, Gayfer 1992, Reimer 1994, Cornwall and Jewkes 1995). This paper provides a generic overview of the origins of Participatory Action Research and in doing so also looks at the various definitions as well as discusses some of the advantages and disadvantages associated with this research approach.

\section{Origins of Participatory Action Research}

There has long been a growing interest in alternative research paradigms. The search for new alternatives came from professionally trained researchers who found their paradigms inadequate to answer all the questions they had (Tandon 1981). With the development of alternative research paradigms, common folk (such as the poor, illiterate, and rural people) began to initiate many successful development efforts (Tandon 1981). Many of these alternative initiatives led to the creation of what would later be called "Participatory Action Research." The term "Participatory Action Research " (hereafter referred to as PAR) is an umbrella term that includes several traditions of theory and practice. Definitions vary according to traditions and users (Brown 1993). St. Denis (1992) notes that often authors coin their own terms to describe their methods and methodologies, even though they are basically similar to one another. Other terms that are used in the literature to describe PAR include participatory research, action research, praxis research, participatory inquiry, collaborative inquiry, action inquiry, and cooperative inquiry (Whyte 1991). 
The origins of Participatory Action Research emerged out of development projects by oppressed people in Third World countries and entered Englishlanguage awareness during the 1970s. Much of Participatory Action Research was driven by humanistic urges to assist the "victims of oligarchies" and their "development" policies. One of the earliest influences on Participatory Action Research approaches came from the Brazilian adult educator, Paula Freire. Freire is well know for his support of the liberation struggles of colonized peoples in the rural areas of Latin America. Friere's ideas have in turn influenced many generations of adult educators in many parts of the world.
According to two early architects of PAR (Tandon 1981 and Hall 1975), two interrelated forces became instrumental in the emergence of PAR:

1. Dominant research paradigms were seen as being insufficient and oppressive; and

2. Dominant research paradigms exploited a large majority of people in underdeveloped countries.

Classical or dominant research paradigms are premised upon notions of neutrality and objectivity. In the dominant paradigms' ongoing exploitation, it assigned the title of "professional expertise" to researchers, which implies that only professionally trained individuals can undertake to do research. Neutrality and objectivity became the hallmark of the research process. According to these paradigms, only professionally trained persons have the capacity to be neutral and objective (Tandon 1981, Hall 1975). Those considered to be "professionally trained" usually come from sectors of society that "have it all" (Tandon 1981: 21). All of these reasons (and many others too numerous to mention) precipitated the need for finding an alternative research method that would replace the exploitative elements of the dominant research paradigms. It had to provide an avenue for those people traditionally underrepresented in society the opportunity to gain access to knowledge and action for improving their situations (Tandon 1981, Almeida, et al 1983).

The origins of PAR emerged out of development projects by oppressed people in Third World countries and entered English-language awareness during the 1970s (Brown and Tandon 1983, Gayfer 1992, Frideres 1992, and Fals-Borda 1992). Much of PAR was driven by humanistic urges to assist the "victims of oligarchies" and their "development" policies (Fals-Borda 1992). One of the earliest influences on PAR approaches came from the Brazilian adult educator, Paula Freire. Freire is well know for his support of the liberation struggles of colonized peoples in the rural areas of Latin America (Brown and Tandon 1983, Jackson, et al 1981, Hall 1981, Frideres 1992, Gayfer 1992, Cornwall and Jewkes 1995, and Cain 1977). Friere's ideas have in turn influenced many generations of adult educators in many parts of the world. It is rare to read a book, article or thesis on literature, population, education or social transformation that does not acknowledge Friere, directly or indirectly (Gayfer 1992: 19). Budd Hall (1981) noted that

Freire was the first to articulate the connection between learning and political transformation and to validate that the work of socially aware educators and others were not marginal, but a key to transformation (Gayfer 1992: 19).

Friere's approach to adult education engaged individuals in critical analysis and organized action to improve their dismal situations (Brown and Tandon 1983). His work affirmed that peoples' own knowledge is valuable to community development and the research process (Cornwall and Jewkes 1995).

Freire first came to the attention of English readers in 1969 through the Harvard University (Heaney 1993). Today, Freire's writings are commonly included in required bibliographies of graduate programs in adult education. His books, once banned in his native Brazil, are now used to guide the training of those in the Brazilian military and local universities (Heaney 1993). Although PAR came later and developed independently of Freire, today Freire would be considered one of PARs staunchest supporters (Gayfer 1992).

At first PAR was either ignored or roundly condemned by other researchers the world over (Heaney 1993, Gayfer 1992). But by the 1970 s and early 1980 s, PAR not only became an interesting topic of discussion, it also quickly became the subject of academic discourse in graduate programs and a favorite topic at respectable conferences around the 


The shift of Participatory
Action Research into
North America created
opportunities to work with
traditionally disadvantaged
peoples and social
movements, such as Latin
American immigrants and
First Nations Councils.
Participatory Action
Research has addressed
women's issues as well as
the issues of peoples with
disabilities. Participatory
Action Research has also
served as a tool of the
Aboriginal movement in
Canada, particularly with
concerns surrounding
health, social and economic
issues.

The shift of Participatory

Action Research into

North America created opportunities to work with traditionally disadvantaged movements, such as Latin American immigrants and First Nations Councils. Participatory Action Research has addressed women's issues as well as the issues of peoples with disabilities. Participatory served as a tool of the Aboriginal movement in Canada, particularly with concerns surrounding issues. world (Heaney 1993). One university even established a "center" for participatory action research (Gayfer 1992). A major advocate of PAR since 1975 has been the International Council for Adult Education (ICAE) (Frideres 1992). ICAE is an international network of participatory researchers, which held the first international forum on participatory research in Yugoslavia in April 1980 (Gayfer 1981). PAR as an alternative or collective approach to social investigation was introduced to readers in 1975 issues of Convergence (Vol. 8, No. 2). In this issue, Budd Hall called for assistance to develop this methodology, which brought forward both an enthusiastic international response as well as blasts of hostility and criticism from then elite and dominant professional circles (Hall 1981, Gayfer 1992). These responses gave rise to the development of a participatory network during 1977 and 1978 as a program of ICAE. This partnership with ICAE came about because it appeared that PAR, with its emphasis on "people as experts," shared a common premise with adult education (Hall 1981). According to Gayfer (1981), who was the editor of Convergence at the time, and Hall (1981), this network was comprised of autonomous centers from Africa, Asia, Europe, Latin America and North America, with increased interest shown by educators in the Caribbean and Arab regions.

Convergence provided an update on PAR in the 1981 edition (Vol. 14, No. 3) and continues to publish numerous articles on PAR discourse (Gayfer 1992).

Although PAR had its origins in Third World countries, Third World countries are not the only countries where PAR methodology is being conducted. By the late 70s, participatory research work was well underway throughout the world. Subsequent projects brought participatory research from the developing countries to urban and rural North America and to various disciplines, including public health, sociology, economics, anthropology, history, community development initiatives, theology, philosophy and social work (Fals-Borda 1992, Frideres 1992, Reimer 1994, and Cornwall and Jewkes 1995). This awareness increased the realization of knowledge as power, an idea first espoused by Paulo Freire in his major publication Pedagogy of the Oppressed" (Gayfer 1992, and Frideres 1992).

The shift of PAR into North America created opportunities to work with traditionally disadvantaged peoples and social movements, such as Latin American immigrants and First Nations Councils (Hall 1993). PAR has addressed women's issues (Hall 1981, Maguire 1987, Gayfer 1992, Barnsely and Ellis 1992) as well as the issues of peoples with disabilities (Barnsley and Ellis 1992). PAR has also served as a tool of the Aboriginal movement in Canada, particularly with concerns surrounding health, social and economic issues (Jackson, et al 1982).

In Canadian social work, BrantCastellano (1986) noted its usefulness in resolving the widespread crisis experienced by Aboriginal families and communities in relation to the reform of Aboriginal Child welfare during the early 1980s. According to Brant-Castellano, PAR was initiated because the surrounding society pre-empted the community's right to work out their own solutions respecting family matters and, in attempting to help, compounded their problems (52). With the help of PAR, a healing process began that was initiated by Aboriginal Peoples, and with the determination that their own knowledge would never again be overridden by outside expertise.

Activist researchers in the Tansanian Bureau of Resource Allocation and Land Use Planning Project are considered, in the literature available, to be the first to use the term "participatory research" (Gayfer 1992). This term was used to describe an experimental pilot project survey with 46 villages in Tanzania, as part of the selfreliance campaign on village development. Their approach scoffed at the social 
Many researchers have

described PAR as being

an integrated approach to

research that involves the

participation of community

members. Maguire, in

particular, described

Participatory Action

Research as an alternative

style of research, which

uses a three-part process

of social investigation,

education and action to

share in the creation of

social knowledge with

oppressed people. science research myth of objectivity and neutrality as well as the sanctity of survey methods with a simple principle:

Villagers themselves as active participants in a research plan that would ultimately motivate them to evaluate their own strengths and needs for the development of their villages (Gayfer 1992: 20).

The Tanzanian experience foreshadowed some basic tenets of PAR:

... faith in the capacity of ordinary people to learn, to name their reality, to become their own researchers in seeking answers to the questions of their daily lives and survival; the inquiry as a collective and educative process; participation in agendasetting, data collection and analyses; and control over outcomes (Gayfer 1992: 20-21)

\section{Defining Participatory Action Research}

No one owns PAR nor is a step-bystep "cook book of recipes" for doing PAR available (Gayfer 1981 and Hall 1975). Because there are no hard and fast rules respecting how PAR should be implemented, it is a process easily adaptable to many researchers and research situations. Some of the common values underlying PAR, as identified by Hall (cited in Ryan and Robinson 1990 and Cain 1977) include:

1. The problem originates in the community itself and the problem is defined, analyzed and solved by the community;

2. The ultimate goal of research is the radical transformation of social reality and the improvement of lives of the people involved. The beneficiaries of the research are the members of the community itself [rather than researchers];

3. Participatory research involves the full and active participation of the community in the entire research process [from beginning to end];
4. Participatory research involves a whole range of powerless groups of people: the exploited, the poor, the oppressed, the marginal, [including Aboriginal peoples], etc.;

5. The process of participatory research can create a greater awareness in the people of their own resources and mobilize them for self-reliant development;

6. It is a scientific method of research in that the participation of the community in the research process facilitates a more accurate and authentic analysis of social reality; and

7. The researcher is a committed participant and learner in the process of research, which can lead to militancy on his/her part, rather than detachment (Ryan and Robinson 1990, Cain 1977: 11-12).

Many researchers (Hoare et al 1993, Ryan and Robinson 1990, Simonson and Bushaw 1993, Reardon et al 1993 and Lammerick 1994) have described PAR as being an integrated approach to research that involves the participation of community members. Maguire (1987), in particular, described PAR as an alternative style of research, which uses a three-part process of social investigation, education and action to share in the creation of social knowledge with oppressed people. In more detail, Maguire described PAR as a method of social investigation of problems, involving the participation of oppressed and ordinary people in problem posing and solving. It is an educational process for the researcher as well as the participants, who analyze the structural causes of named problems through collective discussion and interaction. Maguire recognized that PAR is a way for researchers and oppressed peoples to joint in solidarity to take collective action, from both a short and long term basis, toward radical social change. Maguire notes that participatory research aims at three types of change:

- Development of critical consciousness of both researcher and participants; 
A Review of the Literature on the Benefits

and Drawbacks of Participatory Action Research

Participatory Action
Research is often
illustrated in the literature
as involving the full and
active participation of the
community in the entire
process from start to finish.

Participatory Action

as involving the full and

active participation of the

process from start to finish.
- Improvement in the lives of those involved in the research process; and

- Transformation of fundamental societal structures and relationship (29).

Barnsley and Ellis (1992) in their publication Research for Change: Participatory Action Research for Community Groups, defined PAR as being a "community directed process of collecting and analyzing information on an issue or situation for the purposes of taking action and making change" (90). A community directed approach means that community members assist the researcher while at the same time empower themselves in the ongoing investigation of the social reality of their community. PAR helps the participants build local skills and the capacity to increase their community's autonomy (Maguire 1987, St. Denis 1992 and Hoare et al 1993).

PAR is often illustrated in the literature as involving the full and active participation of the community in the entire process from start to finish (Maguire 1987, Barnsley and Ellis 1992, and Hoare et al 1993, Simonson et al 1993 and Lammerick 1994). Fals-Borda characterizes PAR as:

... part of social activism, with an ideological and spiritual commitment to promote people's (collective) praxis. That informally or formally, the life of everybody, as part of the PAR research is a kind of praxis (1992: 15).

Community members have a role to play in setting the agenda of enquiry; they also participate in the data collection and the analysis of documentation generated over the course of the research and more importantly, participants have more control over the use and outcome of the whole research process. In a nutshell, PAR means doing research "with" rather than "on" people (Maguire 1987).

At least five fields of practice have made contributions to PAR approaches: (1) action research in organizations; (2) participatory research in community development; (3) action research in schools; (4) farmer participatory research and technology generation; and (5) participatory evaluation. According to the literature review of PAR by Deshler and Ewert (1995) PAR has also been used in conjunction with architecture and community planning, landscape ecology design, and environmental and land use planning. The fields of practice that have contributed to PAR are discussed briefly below as an introduction.

Action research in organizations is extensively used in the field of organizational behavior and organizational development in industry and business organizations by management embracing human resource theories, specifically associated with the socio-technical systems perspective that has focused on the fit between technical and social systems (Deshler and Ewert 1995). This tradition has it roots in Latin America and was strongly influenced by concepts such as critical thinking, critical consciousness, conscientization, and empowerment by Paulo Freire in the late 1960s (Deshler and Ewert 1995). Among the major authors representing this tradition are David Brown (1992), Ken Readon, Welsh, Kreiswirth and Forrester (1993) and William Foot Whyte (1992).

Participatory Research in Community Development is considered to be a process of combining education, research and collective action on the part of oppressed groups working with popular educators and community organizers. The knowledge that is generated is intended to help solve practical problems within a community and, ultimately, contribute to a fairer and more just society. Its primary purpose is to encourage the poor and oppressed and those that work with them to generate and control their own knowledge. It assumes that knowledge generates power and that people's knowledge is central to social change (Deshler and Ewert 1995). Authors that represent participatory research in community development include: Orlando Fals-Borda (1992), Budd Hall (1975, 


While conventional
research strategies have
been identified as being
inadequate, researchers
agree that participatory
action research, while
preferable, is not a simple
alternative.

While conventional research strategies have inadequate, researchers agree that participatory action research, while alternative.
1981), McCall (1981), Rajesh Tandon (1981), Brown and Tandon (1983), Patricia Maguire (1987), Readon et al (1993) and Barnsley and Ellis (1992).

Action Research in Schools advocates that teachers should control the educational research agenda and participates in conducting inquiries to test the worth of educational knowledge (Deshler and Ewert 1995). Some of the authors identified with action research in schools include Simonson and Bishaw (1993) and Husen (1988).

Farmer Participatory Research and Technology Generation are also known as "participatory technology development." Mainly agricultural researchers and other instrumental rural development workers developed this approach gradually as an alternative to the traditional "transfer of technology" or "top-down" approach to agricultural research and extension. It emerged from farming systems research and emphasizes the participation of farmers in technology generation, testing, and evaluation to increase or promote sustainable agricultural production and natural resource management (Deshler and Ewert 1995). Another form within this tradition is "participatory rural appraisal," a process that involves villages in a situation analysis that can lead to further participatory documentation of local knowledge and agriculture and natural management experiments. The acknowledgement of the value and importance of Indigenous or local knowledge accompanied the formulation of participatory technology generation (Deshler and Ewert 1995). Major authors associated with this approach include Schensul (1987) and Cornwal and Jewkes (1995).

Lastly, Participatory Evaluation as described by Deshler and Ewert (1995) emerging out of responses to concerns that program evaluations were being under-utilized and that participation on the part of stakeholders would increase their use. Reflection on the relationship of program evaluation practice as a way of serving the public's interest led to participatory evaluation that could serve democratic ideals of social justice and equity. A similar recognition occurred in the evaluation of international programs of community health, rural development, literacy, agriculture, and natural resource management that involving people who are on the receiving end of development in evaluations is likely to assure that most efficient allocation of scarce resources and early identification of ineffective or wasteful use of those resources. This tradition emphasizes that people on the receiving end are ultimately the best judges of whether or not benefits have been produced. Among the major authors representing this approach are Norman Uphoff (1992) and Gail Reimer (1994).

\section{The Challenges of PAR}

While participatory methodologies seem to be all the rage these days, many researchers (Hall 1981, Conchelos and Kassam 1981, Pigozzi 1982, Simonson et al 1993, and Cornwall and Jewkes 1995) have expounded upon some of the possible negative elements and pitfalls associated with participatory action research. While conventional research strategies have been identified as being inadequate, researchers (in particular Tandon 1975, Hall 1981, Conchelos and Kassam 1981, St. Denis 1992, Reimer 194, and Cornwall and Jewkes 1995) agree that participatory action research, while preferable, is not a simple alternative.

Some academics (most notably Cornwall and Jewkes, 1995) have noted that when engaged in participatory action research that "working with local people is far from easy" (1673). Some of the factors that make it difficult for researchers to conduct participatory research include the fact that not everyone within the community will want to partake in participatory research. Add to this the fact that local people may be skeptical about the perceived benefits of the research and as such, may not want to invest their time 


\author{
Researchers who utilize \\ participatory methods must \\ be very careful to recognize \\ that no two groups of \\ peoples or communities are \\ ever homogenous. Within \\ groups and/or communities, \\ there exists a multitude \\ of interrelated axes of \\ differences, including \\ wealth, gender, age, \\ religion, health, ethnicity \\ and power
}

and energy into any research project. In relation to this, Cornwall and Jewkes note that community participation often carries more significance for outsiders than it does for those within the community. Even if there is interest by community members in the research project, there may be the added barriers of time as participation in any research related activity is time consuming. Most individuals, especially those living within oppressed economies, are too busy trying to secure the basic necessities of life to participate in research activities (Cornwall and Jewkes 1995).

Cornwall and Jewkes (quoting Madan 1987) remind researchers that participating communities are "made" rather than "born." Further, that involvement by the community members may not always be continuous or predictable. Participants can experience task exhaustion and the composition of the research group(s) can fluctuate over time. Researchers must be careful to tread softly between the need to generate sufficient interest for the research project and at the same time avoid raising false hopes within the community. They also suggest that the limitations of the research should be honestly identified at the outset so that the establishment of trust within the community is not compromised. Trust can be compromised if participation leads to frustration for participants if they think benefits might be available through participation but then find that knowledge about benefits in no way translates into or guarantees access to benefits (Pigozzi 1982). St. Denis (1992) warns that if people do not understand the research being conducted and/or do not have the opportunity to negotiate a direction for the research to take; they will be reluctant to participate in the research. She further postulates that community people are not academics, and they will not take seriously or get involved in a research project that they do not understand. Even the concept of research as something that can benefit the community, in of itself may be an alien concept to the community (St. Denis 1992).
Hall (1981) recognized early that there are some dangers for participants under participatory action research. Hall noted that social science researchers often gravitate toward participatory research as a way to get people to agree to a position, an action, or a policy, which others (e.g. social workers, adult educators, etc.) feel is important to their purposes. These purposes are not necessarily the same purposes of the participants or communities. In this way PAR can be used as an effective and manipulative "tool" for getting the predominant views of the state into the heart and minds of those that oppose the predominant views (Hall 1981, St. Denis 1992). A good example of such an approach is the consultation approach the Department of Indian Affairs in Canada endorsed through the much-anticipated revision of the Indian Act by Minister Nault's promotion of the First Nations Governance Act. In such instances, PAR is used as a coercive instrument, which governments can use to subtly brainwash those who resist the dominant position.

Researchers who utilize participatory methods must be very careful to recognize that no two groups of peoples or communities are ever homogenous. Within groups and/or communities, there exists a multitude of interrelated axes of differences, including wealth, gender, age, religion, health, ethnicity and power (Cornwall and Jewkes 1995). Researchers as a result, must be cognizant of competing, contested and changing versions of what constitutes "community needs" and/or "values." Added to this is the need to be aware that different definitions will emerge depending upon which interest group is consulted and accordingly to the way in which these groups or communities interpret the researchers' intentions (Cornwall and Jewkes 1995).

In utilizing PAR methodologies, researchers can be caught in a catch-22 situation depending upon whom they align themselves with upon initial contact with communities and/or groups. Research has 


Participatory action
research can also bring
other unintended negative
consequences to those who
participate. Participants
may become alienated
from their community by
virtue of their association
with the research project.
For instance, a heightened
awareness by a marginal
group of its oppression can
increase unhappiness

Participatory action

research can also bring other unintended negative participate. Participants may become alienated from their community by virtue of their association with the research project. For instance, a heightened group of its oppression can increase unhappiness been noted to be more easily facilitated if it is organized through the medium of dominant stakeholders or "leaders," who are often most able to mobilize resources, interest and articulate concerns about the research project. However, the problem with utilizing these individuals may mean, "inviting manipulation of the research according to the agendas of the powerful" (Cornwall and Jewkes 1995: 1673). On the other hand, working outside the power structures can weaken both the potential impact of the project at a wider level, as well as invite continued marginalization of the people and goals of the project (Cornwall and Jewkes 1995).

Participatory action research can also bring other unintended negative consequences to those who participate. Participants may become alienated from their community by virtue of their association with the research project. For instance, a heightened awareness by a marginal group of its oppression can increase unhappiness (Cornwall and Jewkes 1995). In the extreme opposite, participants might come to view themselves as, or align themselves with, the elite. Some projects have resulted in the creation of a participating elite among the local people. That is, participants come to believe that his or her newly gained skills or knowledge somehow make them superior to non-participating members within their communities (Pigozzi 1982). Pigozzi noted that in one participatory situation, those participating in the research project "considered non-participants as stupid, at best" (11). Researchers must be conscious of these kinds of attitudes that which, when cultivated under the participatory process, can foster factionalism within a community.

Factionalism sometimes exists irrespective of the introduction of participatory research activities. For instance, Pigozzi (1982) pointed out that within some participatory relationships (especially in Third World countries), there already exist class structures (whether they be real or perceived) which researchers should be aware of. Researchers must be aware of the local constraints that enable class systems to exist. And further, that the participatory process can be affected by such factors as class tensions, factionalism and ethnicity, which can have direct impact upon participatory research. In acknowledging that these factors have relevance, researchers might benefit from understanding how these factors might be affected by project activities and vice versa (10). To bring home this point, Pigozzi highlighted a story about rickshaw pullers and how participation contributed to factionalism rather than eradicating unfair structures that previously existed:

Within the cooperative program of the Comilla Project rickshaw pullers were one of the disadvantaged groups. Each puller rented a rickshaw at a high daily rate, which he paid to the owner from his daily earnings. A group of pullers asked help in forming a cooperative. Each contributed a portion of daily earnings to the cooperative so that each member could eventually own a rickshaw. It worked. Within the relatively short period of time, each puller had become his own master through following simple cooperative principles (10).

As successful as this story sounds, Pigozzi states that it failed to captivate the negative outcomes that resulted from this participatory endeavor. The rickshaw pullers, becoming themselves owners, ended up repeating the very same exploitative cycle all over again. By hiring out their newly acquired rickshaws at high rates to other pullers less fortunate than themselves, they perpetuated the same exploitative mentality (Pigozzi 1982: 10). Pigozzi stresses that it is important researchers recognize what participatory research and the education associated with it can do to participants and what its limitations are (11).

There are other parties that have direct involvement in participatory activities. The role of these third parties has remained silent in most of the literature 


Funders of research
projects can play a major
part in wielding influence
over the research project
and process. For instance,
Hall noted influence can
be exercised by utilizing
funding policies to expand
procedures that regulate
certain groups within
society and he cites
two examples such as
immigrants and Aboriginal
Peoples. Intervention and
influence is especially
predominant in situations
where the research is
funded by government
sources.

Funders of research

projects can play a major part in wielding influence and process. For instance, Hall noted influence can be exercised by utilizing funding policies to expand procedures that regulate certain groups within two examples such as immigrants and Aboriginal Peoples. Intervention and influence is especially predominant in situations where the research is sources. on participatory action research. However, some scholars (most notably Hall 1981, Conchelos and Kassam 1981, and Cornwall and Jewkes 1995) have identified their concerns with the role of third parties in participatory action research. Third parties can include funding and sponsoring agencies as well as government officials and its bureaucracy. Funders of research projects can play a major part in wielding influence over the research project and process. For instance, Hall (1981) noted influence can be exercised by utilizing funding policies to expand procedures that regulate certain groups within society and he cites two examples such as immigrants and Aboriginal Peoples. Intervention and influence is especially predominant in situations where the research is funded by government sources. In such situations, the researcher is rarely given complete discretion to carry out research in the manner he or she sees fit. The third party may intervene in a variety of ways from demanding practical results of a certain sort at a certain time or demand project documentation at awkward moments and points of time during the life of the research project. Thus, the results generated by the research can ultimately run the risk of becoming a programmed product of the third party or sponsoring agency rather than being owned by the researcher and the participants of the research project (Conchelos and Kassam 1981).

It is important to note that the participatory process has political dimensions attached to it as well. Participation, especially when it is linked to decision-making, is political because change through participation often demands change in the distribution of power (Pigozzi 1982). Under such circumstances, Pigozzi elucidated that:

Those who are threatened by a redistribution of power have, in their own best interest, responded in predictable ways. Usually they try to prevent loss of power (or resource control) by making it difficult to operate or continue research or development projects that facilitate the confrontation of power structures by the disadvantaged (12).

Thus, researchers who advocate participatory methods must be cognizant and aware that the response of the rich and/or powerful might not always be one of accommodation to the project, the researcher, or the participants in the project. Again, Pigozzi cites an extreme example of non-accommodation by the local elite to attempts by the powerless to lessen the gap between the rich and the powerless. In this example, 15 pheasant participants were killed when a projectmeeting center was burned down. The fire was attributed to a coalition of local elites who allegedly were threatened by the power that the cooperating participants might be able to wield (13). Pigozzi concludes that participatory projects that are political by virtue of their goals may run into difficulties imposed from the outside during implementation. However, Pigozzi also states that participatory projects need not always have such dire effects to be problematic. He states that if participation is supposed to enhance benefits in some way, then the very absence of outcomes and benefits can be considered to be a negative result of participation (13).

It is primarily through the participatory venue that researchers have been provided with insights and views that they ordinarily would not have access to or know about. One of the earliest proponents of PAR (Budd Hall) had this to say about participatory action research:

It would be an error to assume that naive or uncontrolled use of participatory research results in strengthening the power of the powerless, for experience has shown that power [under PAR methods] can easily accrue in those already in control (15).

As a result, researchers have gained more power for themselves within the academic status quo and this has fed ideological control by giving more power 


Participatory Action
Research attempts to
undo the monopoly over
knowledge production by
universities and within
the hands of Aboriginal
peoples it can be used as a
powerful tool among many
methods that empower and
reflect ways of knowing,
being and doing that are
culturally endemic to
diverse Aboriginal societies
in Canada.

Participatory Action

Research attempts to undo the monopoly over knowledge production by universities and within the hands of Aboriginal peoples it can be used as a powerful tool among many methods that empower and reflect ways of knowing, culturally endemic to in Canada. to the institutions that researchers do research for (Hall 1981: 15). Moreover, most academic researchers are ill prepared to do participatory research simply because they have been taught to consider themselves and Western scientific knowledge as superior (Colorado 1988, and Cornwall and Jewkes 1995). Within this milieu, research is given artificial neutrality. Training instills in researchers notions of "objectivity" and the "purity" of science that numbs them to the political realities of life in the real world of those they conduct research on and/or with (Colorado 1988; Cornwall and Jewkes 1995). On the other hand, it has also been highlighted by some academics (e.g. Cornwall and Jewkes 1995) that the participants drawn from local communities, like academics, carry their own biases, prejudices and beliefs into participatory research. While their local knowledge and connectedness into local networks can enhance communication and commitment, in some contexts it may be inappropriate to engage local people in certain types of participatory research projects. Cornwall and Jewkes highlighted an example of research being done in Uganda on HIV/AIDS, where it was necessary to employ non-local individuals to collect sensitive data so as not to further stigmatize the local people who had contracted HIV/AIDS (1674). In this project, it was necessary to shelter the privacy of these people from the community members who did not have the HIV/AIDS virus/disease.

Another disadvantage highlighted by Reimer (1994) as to community impressions of PAR, relate to the inherent relationship outside researchers have with local individuals that are hired to assist in the research process. Individuals that are hired under the rubric of "co-researcher" may have ambivalent feelings about their role in the research process. He or she may know that his or her role encompasses more than just interpreting for the principle researcher. However, to other community members, he or she may not be seen as being a "researcher" simply because he or she has not received the formal education or training to become a "researcher." As a result, those community members who have not yet had direct participation in the research project will see these individuals as merely "helpers" rather than legitimate "co-researchers." Reimer points out that the history of colonialism within the research enterprise and the relationship of research dynamics is impossible to eradicate. Much work remains to be done to "decolonize" and "de-mystify" social science research being done particularly in Aboriginal communities (Reimer 1994).

\section{Conclusion}

This piece has attempted to define PAR and map its origins. It has outlined advantages and disadvantages as identified in the prevailing literature that have evaluated PAR as a primary research method. As highlighted there are benefits coupled with weaknesses in choosing PAR as a method of doing research. PAR attempts to undo the monopoly over knowledge production by universities (Hall 1999) and within the hands of Aboriginal peoples, in particular, it can be used as a powerful tool among many methods that empower and reflect ways of knowing, being and doing that are culturally endemic to the diverse Aboriginal societies in Canada. This article merely offers readers and Aboriginal communities as well as researchers an opportunity to choose for themselves whether the advantages as outlined above outweigh the disadvantages or vice versa. While PAR as a research method has been around for close to 35 years, its use in the Aboriginal context of research is still relatively uncultivated however there are many research initiatives undertaken by Aboriginal communities and researchers which have since taken advantage of this powerful approach. 
A Review of the Literature on the Benefits

and Drawbacks of Participatory Action Research

\section{References}

Almeida, E., Sanchez, M.E., Soto,B., Felix,L., \& Perez,V. (1983)

Development of a Participatory Research Centre as Part of an Ongoing Rural Development Program. In The Journal of Applied Behavioral Science, Vol. 19, No. 3: pp. 295-306.

Barnsley, J. and D. Ellis. (1992). Research for Change: Participatory Action Research for Community Groups. Vancouver: The Women's Research Centre.

Brant-Castellano, Marlene. (1986). Collective Wisdom: Participatory Research and Canada's Native People. In Convergence: An International Journal of Adult Education, 19 (3): pp. 50-53.

Brown, L.D. and R. Tandon. (1983). Ideology and Political Economy in Inquiry: Action Research and Participatory Research. The Journal of Applied Behavioural Science, 19 (3): pp. 277-294.

Brown, L.D. (1985). People-Centered Development and Participatory Research. Harvard Educational Review, 55(1): pp. 69-75.

Brown, L.D. (1993). Becoming a PAR Practitioner. In Profiles of Participatory Action Researchers, Forester, J., J. Pitt, and J. Welsh (Eds.). Ithica, NY: Cornell University, Einaudi Centre for International Studies and Department of City and Regional Planning. (missing page numbers).

Cain, B. (1979). Participatory Research: Research with Historic Consciousness. PRP Working Paper No. 3. Toronto: Participatory Research Project.

Colorado, P. (1988). Bridging Native and Western Science. In Convergence: An International Journal of Adult
Education, Vol. 21, No. 2/3: pp. 49-67.

Conchelos, G. and Y. Kassam. (1981). A Brief Review of Critical Opinions and Responses on Issues Facing Participatory Research. In Convergence: An International Journal of Adult Education, 14 (3): pp. 52-64.

Conchelos, G. (1985). “Participatory oral history research in native communities: Some problems and emerging guidelines for doing it." Paper presented for the Conference on Participatory Research for Community Action. University of Massachusetts at Amherst.

Convergence: An International Journal of Adult Education, 8 (2).

Cornwall, A. and R. Jewkes. (1995). What is Participatory Research? Social Science Medicine, 41(12): pp. 1667-1676.

Deshler, D., and Ewert, M. (May 25, 1995). Participatory Action Research: Traditions and Major Assumptions. The PAR Tool Box: Part \#001, Last Updated: May 25, 1995 http://www. PARnet.org/parchive/docs/deshler 95/

Fals-Borda, O. (1992). Evolution and Convergence in Participatory Action Research. In A World of Communities: Participatory Research Perspectives, James S. Frideres (Ed.). North York, ON: Captus University Publications: pp. 14-19.

Flaherty, M. (no date). Freedom of Expression or Freedom of Exploitation? Speech to the Association of Canadian Universities for Northern Studies 4th National Students' Conference on Northern Studies. Paper prepared for the Pauktuutit Inuit Women's Association.

Frideres, J. (1992). Participatory Research: An Illusionary Perspective. 


\section{First Peoples Child \& Family Review, Volume 1, Number 1, 2004}

In $A$ World of Communities: articipatory Research Perspectives, James S. Frideres (Ed.). North York, ON: Captus University Publications: pp. 1-13.

Gayfer, M. (Ed.). (1981). Participatory Research: Developments and Issues. Convergence: An International Journal of Adult Education, 14 (3): 1.

Gayfer, M. (1992). The Sound of People Learning and Organizing for Change. Convergence: An International Journal of Adult Education, 25 (4): pp. 17-25.

Hall, B. (1975). Participatory Research: An Approach for Change. In Convergence: An International Journal of Adult Education, 8 (2): pp. 24-31.

Hall, B. (1981). Participatory Research, Popular Knowledge and Power: A Personal Reflection. Convergence: An International Journal of Adult Education, 14 (3): pp. 5-17.

Hall, B. (1999). "Poor People Do Not Use Money as a Weapon": Reflections on the Beginnings of Participatory Research. Opening Remarks at the International Participatory Development Conference in Ottawa August 25-28, 1999.

Heaney, T.W. (1993). If you can't beat 'em: The professionalization of Participatory Research. In Voices of Change: Participatory Research in the United States and Canada, Peter Park, May Bydon-Miller, Budd Hall and Ted Jackson (Eds.). Westport, Connecticut: Bergin \& Garvey: pp. 27-46.

Hoare, T., C. Levy, and M.P. Robinson. (1993). Participatory Action Research in Native Communities: Cultural Opportunities and Legal Implications. In The Canadian Journal of Native Studies, 13 (1): pp. 43-78.
Husen, T. (1988). Research Paradigms in Education. Interchange, 19 (1), 2-13.

Jackson, T., D. McCaskill, and B. Hall (Eds.). (1982). Learning for SelfDetermination: Community Based Options for Native Training and Research. Introduction in Special Issue of The Canadian Journal of Native Studies, 2(1): pp. 1-9.

Lammerink, M.P. (1994). People's Participation and Action Research in Community Development: Experiences from Nicaragua. Community Development Journal, 29 (4): pp. 362-368.

McCall, Brian. (1981). Popular Participation, Research and New Alliances. In Convergence: An International Journal of Adult Education, 14 (3): pp. 65-73.

Mandan, T.N. (1987). Community Involvement in health policy: sociostructural and dynamic aspects of health beliefs. In Social Science Medicine, 25: 615.

Maguire, P. (1987). Doing Participatory Research: A Feminist Approach. Amherst: Centre for International Education, School of Education, University of Massachusetts.

Masuzumi, B. and S. Quirk. (1993). A Participatory Research Process for Dene/Metis Communities. Paper prepared for Dene Tracking.

Miller, G.D. (1997). KnowledgeSharing Institutions: A Movement to Transform Change Agents into Exchange Agents. In Community Economic Development: In Search of Empowerment, Eric Shragge (Ed.). Montreal: Black Rose Books: 19-28.

Patton, M.Q. 1982. Practising With and Without Goals. In Practical Evaluation. London: Sage Publications: pp. 100-138. 
A Review of the Literature on the Benefits

and Drawbacks of Participatory Action Research

Pigozzi, M.J. (1982). Participation in Non-Formal Education Projects: Some Possible Negative Outcomes. In Convergence: An International Journal of Adult Education, 25 (3): pp. 6-19.

Readon, K., J. Welsh, B. Kreiswirth, and J. Forrester. (1993). Participatory Action Research from the Inside: Community Development Practice in East St. Louis. In The American Sociologist, Spring: pp. 69-91.

Richer, S. (1988). Fieldwork and the Commodification of Culture: Why the Natives are Restless. In The Canadian Review of Sociology and Anthropology, 25(3): pp. 406-420.

Reimer, G.D. (1994). Community Participation in Research and Development: A Case Study from Pangnirtung, Northwest Territories. Ph.D. Dissertation, McMaster University.

Royal Commission on Aboriginal Peoples (RCAP). (1996). Rekindling the Fire. In Looking Forward, Looking Back, Volume 1 of the Report on Aboriginal Peoples (Ottawa: Canada Communications Group).

Ryan, J. and M.P. Robinson. (1990). Implementing Participatory Action Research in the Canadian North: A Case Study of the Gwich'in Language and Cultural Project. In Culture, 10(2): pp. 57-71.

Schensul, J.J. (1987). Perspectives on Collaborative Research. In Collaborative Research and Social Change, D.D. Stull and J.J. Schensul (Eds.). Boulder and London: Westview Press: pp. 211-219.

Seymour-Rolls,K., \& Hughes, I. (1995). Participatory Action Research: Getting the Job Done. Action Research Electronic Reader, pp. 1-6.
Simonson, L.J. and V.A. Bushaw. (1993). Participatory Action Research: Easier Said Than Done. In The American Sociologist, Spring: pp. 27-37.

St. Denis, V. (1992). Community-Based Participatory Research: Aspects of the Concept Relevant for Practice. In Native Studies Review, 8(2): pp. 51-97.

Stevenson, S. (no date). In Search of Inuit Ecological Knowledge: A Protocol for its Collection, Interpretation and Use. Paper prepared for the Department of Renewable Resources, GNWT, Qikiqiaaluk Wildlife Board and Parks Canada.

Tandon, R. (1981). Participatory Research in the Empowerment of People. In Convergence: An International Journal of Adult Education, 8 (2): pp. 44-53.

Ward, S. (1996). Collaborative Research in Nunavut: The Case of the Mallik Islands Part Study, Cape Dorset, NWT. Masters of Natural Resource Management Practicum, Natural Resources Institute, University of Manitoba.

Warry, W. (1990). Doing Unto Others: Applied Anthropology, Collaborative Researchand Native SelfDetermination. In Culture, 10(1): pp. 61-73.

Westerman, F. (1985). Here Come the Anthros. In Reflections: The Anthroplogical Muse, J. Iain Prattis (Ed.). Washington: American Anthropological Association. (Missing page numbers).

Whyte, William Foote. (1991). Participatory Action Research. London: Sage. 